\title{
A Case Study of Learners' Engagement in Mobile Learning Applications
}

\author{
Chenxi Liu \\ Ana-Paula Correia \\ The Ohio State University, USA
}

\begin{abstract}
Although mobile learning applications play a crucial role in today's education and can support learning, the low retention rate is a prevalent challenge in mobile learning. Existing studies have found that interpersonal interaction, high expectations, and supportive environment (from an educational perspective) as well as compatibility, interactivity, and usability (from a marketing perspective) can impact learners' engagement in learning activities and customers' engagement in mobile applications. However, comprehensive studies investigating learners' engagement in mobile learning applications from educational and marketing perspectives are rare. To fill the research gap, we analyzed learners' reviews on five top-ranked lifelong learning applications (Udemy, LinkedIn Learning, Coursera, edX, and Skillshare). Inductive coding was used to identify critical factors impacting learners' engagement in mobile learning applications, such as usability, availability of learning experiences, features to facilitate learning, interpersonal interaction, and incentives for completion. We further explored specific engagement strategies displayed in the analyzed applications through an analytical evaluation. Besides, this study expands Hew's model of learners' engagement and suggests new conceptual relationships between critical factors impacting learners' engagement, self-determination theory, and learners' engagement.
\end{abstract}

Keywords: mobile learning, engagement, mobile learning application design, lifelong learning

Liu, C., \& Correia, A. (2021). A case study of learners' engagement in mobile learning applications. Online Learning, 25(4), 25-48. DOI: 10.24059/olj.v25i4.2827 
Mobile learning is defined as an extension of digital learning, allowing learners to access information, resources and perform learning activities anytime and anywhere with the assistance of mobile computing devices and information and communication technologies (Qiu, 2019). Previous review studies on mobile learning have found that most mobile learning can produce positive results in education (Wu et al., 2012; Chee et al., 2017). Specifically, mobile learning can effectively improve learners' achievement, motivation, and interests in learning with proper design and development (Hwang \& Wu, 2014).

With the rapid development of mobile applications and online educational resources, mobile learning applications play a crucial role in today's education (Ansari \& Tripathi, 2017). Mobile learning applications can not only facilitate knowledge acquisition and transfer (Hannon, 2017), but also increase retention rates and academic performance (Deb et al., 2017; Pechenkina et al., 2017), and promote learning engagement (Noel et al., 2015). Using mobile learning applications, learners can engage in learning anytime and anywhere (Ansari \& Tripathi, 2017), and their need for personalized learning can also be satisfied (Pechenkina et al., 2017).

Although using mobile applications in teaching and learning brings many advantages, mobile learning applications are facing a common problem of low retention rate. Retention rate is the percentage of users continuing to use an application within a certain number of days since first use (Zuniga et al, 2019). After one month since installation, a $2.5 \%$ retention rate of a mobile learning application is $2.5 \%$, meaning that only 25 out of 1,000 users are still in use after 30 days, which is lower than that of most other types of applications (Statista Research Department, 2021).

Previous research suggested that interpersonal interactions, learning design, and supportive environment can impact learners' engagement in learning activities (from an educational perspective) (e.g., Davis \& Frederick, 2020; Freitas et al., 2015; Hew, 2016). Additionally, compatibility, interactivity, and usability factors that can impact customers' engagement in mobile applications have also been identified (from a marketing perspective) (e.g., Baker, 2020; Fang et al., 2017; Kim \& Baek, 2018). However, few studies have considered both perspectives to investigate learners' engagement in mobile learning applications generally released on the mobile application market for educational purposes.

Online reviews are a crucial source for obtaining users' opinions, inquiries, and requirements on a product (Chen et al., 2019; Pongwat, 2019). Learners' online reviews for mobile learning applications involve their perceptions on both learning and application use. Therefore, this study investigated learners' online reviews for five top-ranked lifelong learning applications, aiming to gain a more comprehensive understanding of factors impacting learners' engagement.

\section{Theoretical Framework}

The concept of engagement has been extensively investigated in both education and marketing (Cheung et al., 2011). Yet, a clear definition of engagement is still challenging due to the disagreement about its attributes (Bond et al., 2020; Cheung et al., 2011; Harris, 2008), which fall into two categories. One claims that engagement consists of three components: behavioral engagement, emotional or affective engagement, and cognitive engagement (Brodie et al., 2011; Fredricks et al., 2004; Trowler, 2010). While the other suggests an additional component, social engagement (Fredricks et al., 2016; Vivek et al., 2012) or agentic engagement (Reeve, 2012). Because the former category is more widely accepted (Bond et al., 2020; Hollebeek, 2011), this study refers to engagement as an individual's behavioral, affective, and cognitive involvement with an activity. 
Learner engagement is often defined as an individual's interaction with activities and conditions conducive to learning and development (Coates \& Radloff, 2012). According to Kuh (2001), learners' engagement consists of participation in meaningful academic activities. Based on the three components of engagement, behavioral engagement is learner participation in learning activities; affective engagement is learner emotional response regarding learning activities; cognitive engagement is learner thinking for a specific task while conducting a learning activity (Fredricks et al., 2004).

Figure 1

Hew's (2016) proposed model of learners' engagement

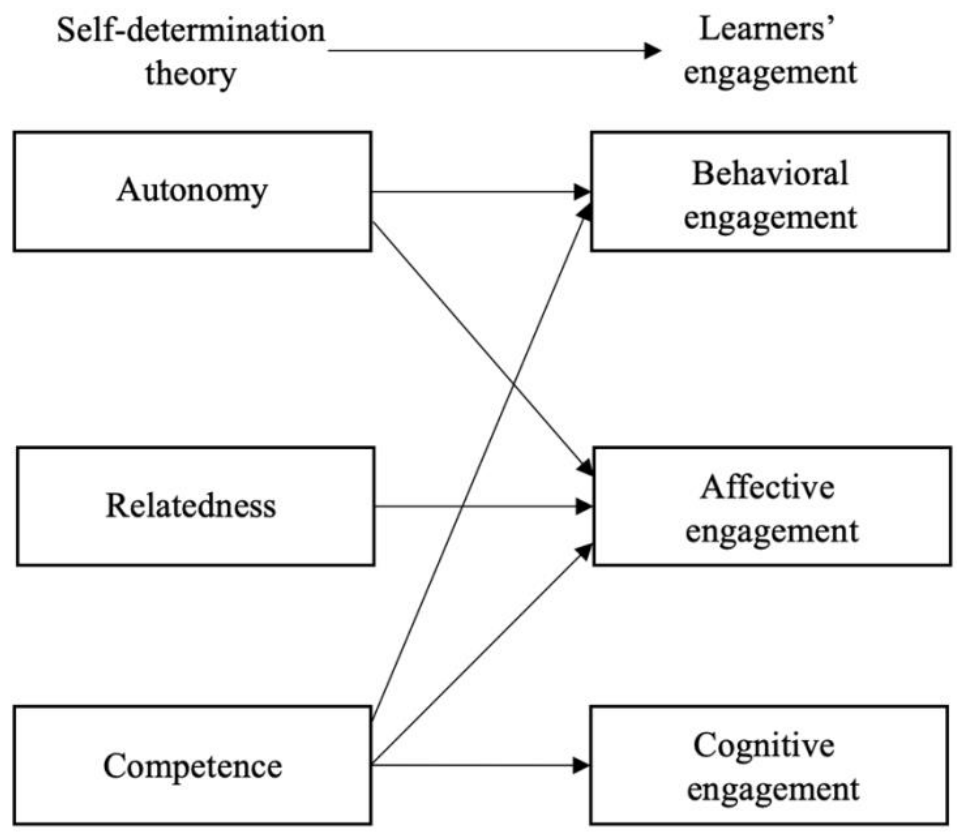

Self-determination theory argues that motivation is affected by three psychological needs: competence, relatedness, and autonomy (Deci \& Ryan, 2008). According to Cooke et al. (2016), "autonomy is defined as volition and choice.... Relatedness represents the level of connectedness to others.... Competence refers to being effective within an environment and able to obtain valued outcomes from it" (p. 633). Hew (2016) proposed a model to demonstrate the connections between the three components of engagement and the three psychological needs of selfdetermination theory. We believe that learners' engagement can be influenced by the three psychological needs (Figure 1). To explore critical factors impacting learners' engagement in mobile learning applications and engagement strategies employed in top-ranked mobile learning applications, this study used Hew's (2016) model as its theoretical lenses.

\section{A Review of Existing Studies}

Mobile learning applications are generally released on the mobile application market for educational purposes. To comprehensively understand how users' engagement in mobile learning applications is affected, it is necessary to review previous studies on learners' 
engagement in diverse learning environments (from the educational perspective) and customers' engagement in mobile applications (from the marketing perspective).

\section{Factors Impacting Customers' Engagement}

Although factors that affect customers' engagement in mobile applications are different depending on the studies, common factors are compatibility, interactivity, and usability. In addition, accomplishment rewards, such as task completion certifications, are particularly emphasized in mobile learning applications.

In the reviewed literature, compatibility refers to customers' perceptions of how mobile applications meet their needs and preferences (Fang et al., 2017). Mobile applications with a high level of customization attributes and personalized adaptation can effectively improve customers' engagement (Fang et al., 2017; Kim \& Baek, 2018; McLean, 2018; Pham \& Chen, 2019).

Interactivity involves customer-to-customer interaction and customer-to-application interaction. Lele (2015) and Dinner et al. (2015) suggested that adding social features to mobile applications facilitated the interaction and communication between customers, therefore increasing customers' engagement. Besides, by enabling mobile applications to appropriately push notifications (Pham \& Chen, 2019; Pham et al., 2016) and send in-app messaging (Baker, 2020; Perro, 2018), customers' attention to mobile applications is grabbed so that their engagement can also be improved.

Usability is a quality attribute of system acceptability (Nielsen, 1993) and refers to the ease with which users can learn to operate and use a system (IEEE, 1990). In the reviewed studies, the aspects related to usability and impacting users' engagement in mobile applications involve ease of use (McLean, 2018; Fang et al., 2017), usefulness (McLean, 2018), convenience (Kim \& Baek, 2018; McLean, 2018), interface design (Fang et al., 2017; Pham \& Chen, 2019; Tarute et al., 2017), and privacy/security (Fang et al., 2017).

Accomplishment reward is a factor that is closely related to mobile learning applications. Pham and Chen (2019) proposed a Personalized Adaptive CARD-based interface (PACARD) to improve learners' engagement with mobile learning applications. By integrating PACARD into an English-language learning mobile application and analyzing engagement-related data (e.g., application retention and time spent), PACARD has been proved to increase learners' engagement in mobile learning applications. Accomplishment reward is one of the factors included in PACARD, and it is reflected in the form of digital badges. By completing specific tasks, learners receive corresponding digital badges as their accomplishment rewards.

Table 1 shows the identified factors impacting customers' engagement in mobile applications. 
Table 1

Summary of Identified Factors Impacting Customers' Engagement

\begin{tabular}{|c|c|c|}
\hline Factors & Description & Research \\
\hline Compatibility & $\begin{array}{l}\text { Mobile applications' customization } \\
\text { attributes and personalized adaptation }\end{array}$ & $\begin{array}{l}\text { Fang et al. (2017); Kim \& Baek (2018); } \\
\text { McLean (2018); Pham \& Chen (2019) }\end{array}$ \\
\hline Interactivity & $\begin{array}{l}\text { 1. Customer-to-customer interaction (e.g., } \\
\text { social features) } \\
\text { 2. Customer-to-application interaction (e.g., } \\
\text { push notifications, in-app messaging) }\end{array}$ & $\begin{array}{l}\text { Baker (2020); Dinner et al. (2015); Lele } \\
\text { (2015); Perro, (2018); Pham \& Chen } \\
\text { (2019); Pham et al. (2016) }\end{array}$ \\
\hline Usability & $\begin{array}{l}\text { Ease of use, usefulness, convenience, } \\
\text { interface design, privacy/security }\end{array}$ & $\begin{array}{l}\text { Fang et al. (2017); Kim \& Baek (2018); } \\
\text { McLean (2018); Pham \& Chen (2019); } \\
\text { Tarute et al. (2017) }\end{array}$ \\
\hline $\begin{array}{l}\text { Accomplishment } \\
\text { rewards }\end{array}$ & e.g., digital badges & Pham \& Chen (2019) \\
\hline
\end{tabular}

\section{Factors Impacting Learners' Engagement}

Interpersonal interaction, curriculum and learning design, achievement motivation, high expectations, and supportive environment are the commonly mentioned factors that impact learners' engagement in diverse learning environments, including online learning, mobile learning, face-to-face learning, and blended learning.

In the reviewed studies, interpersonal interaction primarily includes learner-to-instructor interaction and learner-to-learner interaction. Learner-to-instructor interaction in online learning can be achieved using different strategies. Examples are:

1. Sending announcements or emails (Martin \& Bolliger, 2018).

2. Providing feedback on learners' work (Sadaf et al., 2019).

3. Holding office hours (Hew, 2016).

4. Increasing teacher presence (Hong \& Gardner, 2019).

Learner-to-learner interaction can be enhanced by, for example, working collaboratively (e.g., Guenther \& Miller, 2011; Zepke \& Leach, 2010), participating in discussions (Guajardo Leal et al., 2019; Hew, 2016; Martin \& Bolliger, 2018; Sadaf et al., 2019), and providing peer feedback (Hew, 2016). Freitas et al. (2015) proposed a third model for online learning, which suggested that social interactions should be accounted for one-third of the time for online learning. Sun et al. (2019) claimed that relationship quality, including trust and commitment, significantly and positively impacted learners' psychological engagement in massive open online courses.

In terms of curriculum and learning design, providing authentic learning activities (Buelow et al., 2018; Martin \& Bolliger, 2018), incorporating active learning (Guenther \& Miller, 2011; Hew, 2016), and delivering appropriate course resources (Hew, 2016) are widely recognized strategies to promote learners' engagement. Among those, course resources should meet the needs of different learners by delivering clear learning objectives and instructions, including a wide variety of formats and difficulty levels (Hew, 2016; Sadaf et al., 2019). An appropriate level of difficulty and interactive digital learning content can increase learners' engagement in online learning (Freitas et al., 2015). Through the strategic use of multimedia, learners' engagement in online learning can also be promoted (Buelow et al., 2018; Davis \& Frederick, 2020).

Achievement motivation refers to a person's tendency to participate in achievementdriven behaviors and do things well (Guenther \& Miller, 2011). It corresponds to learners' self- 
belief and inner desire to acquire knowledge. When learners can work autonomously and achieve self-learning goals, achievement motivation can be increased (Guenther \& Miller, 2011; Zepke \& Leach, 2010). Guajardo Leal et al. (2019) claimed that learners with higher levels of motivation were more likely to have higher levels of engagement in online learning.

High expectations include learners' expectations and challenges set by others, such as instructors and schools. High academic expectations created by learners, instructors, and schools have been documented to increase learners' engagement (Guenther \& Miller, 2011). By establishing high academic standards and assigning assessment tasks, teachers can create challenging and enriching educational experiences for learners to improve their learning engagement (Zepke \& Leach, 2010). Sadaf et al. (2019) found that setting clear expectations in online courses could positively impact learners' engagement. And Freitas et al. (2015) claimed that the difficulty level of the assessment had a positive effect on learners' engagement.

A supportive environment consists of instructor support, infrastructure and technical support. Instructor support consists of instructors' accessibility and presence (Hew, 2016; Hong \& Gardner, 2019; Zhang et al., 2016), passion, and differentiated instruction (Hew, 2016). Infrastructure and technical support are established by offering a welcoming and diverse learning environment, providing various support services, and allowing learners to access internet services and devices (Guenther \& Miller, 2011; Tarantino et al., 2013; Zepke \& Leach, 2010).

Table 2 summarizes the identified factors impacting learners' engagement in education.

Table 2

Summary of Identified Factors Impacting Learners' Engagement

\begin{tabular}{|c|c|c|}
\hline Factors & Description & Research \\
\hline $\begin{array}{l}\text { Interpersonal } \\
\text { interaction }\end{array}$ & $\begin{array}{l}\text { 1. Learner-to-instructor (e.g., send announcements } \\
\text { or emails, provide feedback, hold counseling } \\
\text { hours, have instructors present in online } \\
\text { learning) } \\
\text { 2. Learner-to-learner (e.g., participate in online } \\
\text { discussions, work collaboratively, provide } \\
\text { feedback) }\end{array}$ & $\begin{array}{l}\text { Freitas et al. (2015); Guenther \& } \\
\text { Miller (2011); Hew (2016); Hong \& } \\
\text { Gardner (2019); Guajardo Leal et al. } \\
\text { (2019); Martin \& Bolliger (2018); } \\
\text { Sadaf et al. (2019); Sun et al. (2019); } \\
\text { Zepke \& Leach (2010) }\end{array}$ \\
\hline Curriculum \& & 1. Authentic learning activities & Buelow et al. (2018); Davis \& \\
\hline learning design & $\begin{array}{l}\text { 2. Active learning } \\
\text { 3. Course resources (e.g., clear learning objectives } \\
\text { and instruction, a wide variety of resource } \\
\text { formats and difficulty levels, interactive } \\
\text { digital content, multimedia) }\end{array}$ & $\begin{array}{l}\text { Frederick (2020); Freitas et al. (2015); } \\
\text { Guenther \& Miller (2011); Hew } \\
\text { (2016); Martin \& Bolliger (2018); } \\
\text { Sadaf et al. (2019) }\end{array}$ \\
\hline $\begin{array}{l}\text { Achievement } \\
\text { motivation }\end{array}$ & $\begin{array}{l}\text { 1. Learners' self-belief and inner desire to acquire } \\
\quad \text { knowledge } \\
\text { 2. Work autonomously } \\
\text { 3. Achieve self-learning goals }\end{array}$ & $\begin{array}{l}\text { Guajardo Leal et al. (2019); Guenther } \\
\& \text { Miller (2011); Zepke \& Leach } \\
\text { (2010) }\end{array}$ \\
\hline $\begin{array}{l}\text { High } \\
\text { expectations }\end{array}$ & $\begin{array}{l}\text { 1. Set by learners and others } \\
\text { 2. e.g., high standards for acceptable academic } \\
\text { work, high and clear academic expectations, } \\
\text { and difficulty level of assessments }\end{array}$ & $\begin{array}{l}\text { Freitas et al. (2015); Guenther \& } \\
\text { Miller (2011); Sadaf et al. (2019); } \\
\text { Zepke \& Leach (2010) }\end{array}$ \\
\hline $\begin{array}{l}\text { Supportive } \\
\text { environment }\end{array}$ & $\begin{array}{l}\text { 1. Instructor support (e.g., instructors' accessibility } \\
\text { and presence, passion, and differentiated } \\
\text { instruction) } \\
\text { 2. Infrastructure support (e.g., welcome and diverse } \\
\text { learning environment, various support service, } \\
\text { devices and internet accessibility) }\end{array}$ & $\begin{array}{l}\text { Guenther \& Miller (2011); Hew } \\
\text { (2016); Hong \& Gardner (2019); } \\
\text { Tarantino et al. (2013); Zepke \& } \\
\text { Leach (2010); Zhang et al. (2016) }\end{array}$ \\
\hline
\end{tabular}




\section{An Analysis of Online Reviews}

Online reviews have become an important source of information reflecting users' perceptions of a product, which triggered many studies investigating it to facilitate improvements in mobile applications. For instance, Khalid et al. (2015) qualitatively studied the low-rating reviews posted online for $20 \mathrm{iOS}$ applications and identified 12 types of complaints to help developers better understand and address users' concerns. Based on online ratings and reviews, Chen et al. (2019) developed a user requirements mining framework that has been empirically examined to promote the quality upgrade of mobile applications.

In education, Pongwat (2019) investigated learners' online reviews for a mobile learning application. In addition to contributing to the quality evaluation of mobile learning applications, Pongwat's study revealed potential issues application developers need to consider.

According to Tucker and Kim (2011), using online reviews to promote product improvement and design has two notable benefits. First, it enables researchers to access and store large amounts of product review data in a short time. Second, it is based on users' revealed preference (users' feedback on a product after a considerable interaction time) rather than users' stated preference (users' responses to a hypothetical scenario survey). Furthermore, online reviews are highly correlated with application downloads (Harman et al., 2012) and are a crucial measure of an application's quality (Khalid et al., 2015). In summary, we decided to use learners' online reviews as data to address the research questions.

\section{Research Questions}

The current case study investigated learners' online reviews (e.g., reviews posted on App Store and Google Play) of five top-ranked lifelong learning mobile applications to provide a comprehensive understanding of learners' engagement in mobile learning applications. Through inductive coding and analytical evaluation, we answered the following research questions.

Research Question 1: What factors are critical to learners' engagement in mobile learning applications?

Research Question 2: Which engagement strategies are offered by mobile learning applications that promote learners' engagement?

This study relied on Aspin and Chapman's (2000) definition of "lifelong learning for all" as a complex and multi-faceted process, that begins in pre-school, is carried on through compulsory and post-compulsory periods of formal education and training, and is then continued throughout life, through provision of such learning experiences, activities and enjoyment in the home, in the work-place, in universities and colleges, and in other educational, social and cultural agencies, institutions and settings - both formal and informal—within the community. (p. 16)

\section{Research Methodology}

The current study employed a qualitative case study research approach. To answer the research questions above, we first applied inductive coding to identify critical factors impacting learners' engagement in mobile learning applications. We then conducted an analytical evaluation to explore specific strategies those applications offered to promote learners' engagement. 


\section{Data Collection}

The data selection process involved two steps: (1) identify mobile learning applications and (2) collect learners' reviews to ensure comprehensiveness and reliability. In November 2019, AppGrooves was used to identify five top applications from App Store and Google Play. These applications were Udemy, LinkedIn Learning, Coursera, edX, and Skillshare. AppGrooves was used as the application selection tool. This tool collects, reviews, and ranks applications by blending quantitative analysis (data-driven algorithm initially filters high-quality applications) and qualitative analysis (independent editorial team further refines the selected applications) during the review process (AppGrooves, n.d.).

Figure 2

Summary of the data selection process

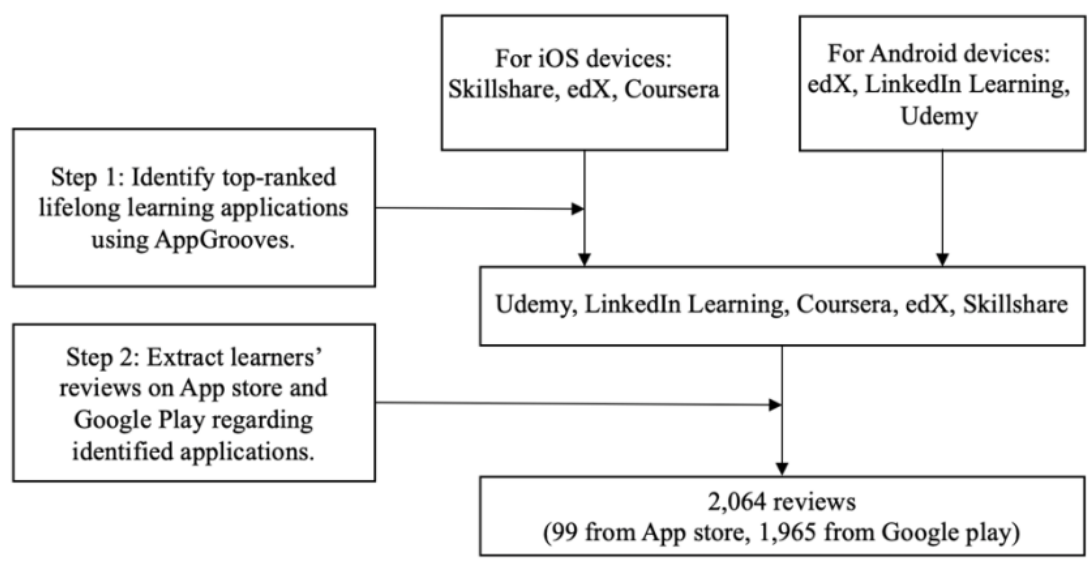

After identifying the mobile learning applications to be analyzed, a total of 2,064 learners' reviews on Udemy, LinkedIn Learning, Coursera, edX, and Skillshare were extracted between November 1 and December 1 of 2019. These included 99 reviews from App Store and 1,965 from Google Play. The learners' reviews analyzed were written in English. Compared with iOS, the Android operating system has a larger market share (Mobile Operating System Market Share Worldwide, 2020) which means that applications on Google Play show more downloads than on App Store. Thus, the number of reviews available on Google Play was higher than that on the App Store. Figure 2 exhibits the summary of the data selection process.

To protect the anonymity and privacy of the study subjects, we only collected the publicly available information needed for this study without including any identifiable information, not even learners' screen names. All the collected data were stored in a cloud drive with password protection and can only be accessed by the researchers. The backup data was stored on one researcher's personal computer, and the laptop was also password protected.

\section{Data Analysis}

This study used inductive coding to identify critical factors impacting learners' engagement in mobile learning applications. Inductive coding is a systematic qualitative data analysis procedure whereby researchers use raw data to derive concepts, themes, or a model through interpretations based on the raw data (Thomas, 2006). Questions best suited for 
qualitative data analysis seek to obtain a deep understanding of a phenomenon (Creswell, 2012). In contrast to quantitative analysis, which is more deductive, qualitative analysis is more inductive (Creswell, 2012). Because researchers do not impose preconceptions in inductive coding, it can reveal critical themes that might be obscured, reframed, or overlooked in deductive coding (Thomas, 2006). Consequently, inductive coding is more appropriate for this study.

This study followed Creswell's (2012) coding process, as shown in Figure 3.

Specifically, we first exported the 2,064 learners' reviews into Microsoft Excel in a standard format with a backup and initially read them. Secondly, we divided these reviews into 2,407 text segments based on their content and relevance to this study. Some reviews were broken down into several segments with different meanings. In contrast, some reviews were excluded from further coding because they were not related to the three psychological needs of selfdetermination theory. Next, after a discussion among the authors, we developed a coding framework to guide the coding based on our understanding of the reviews gained in the previous step. The description of each code was also noted. As more reviews were coded, the coding framework was revised as new codes emerged. Some reviews were re-read and recoded based on the new framework. After labeling all the text segments, we identified a total of 34 codes. Then, we created a list of the 34 codes, carefully grouped similar codes, and remove redundant codes. We reduced the number of codes to 17 . Finally, through analyzing the attributes of the 17 codes and repeatedly reading their corresponding text segments, we further collapsed the 17 codes into five broad themes to answer the first research question. The five themes and the 17 codes are presented in Table 3 as factors and subfactors, respectively.

Figure 3

Summary of the inductive coding process

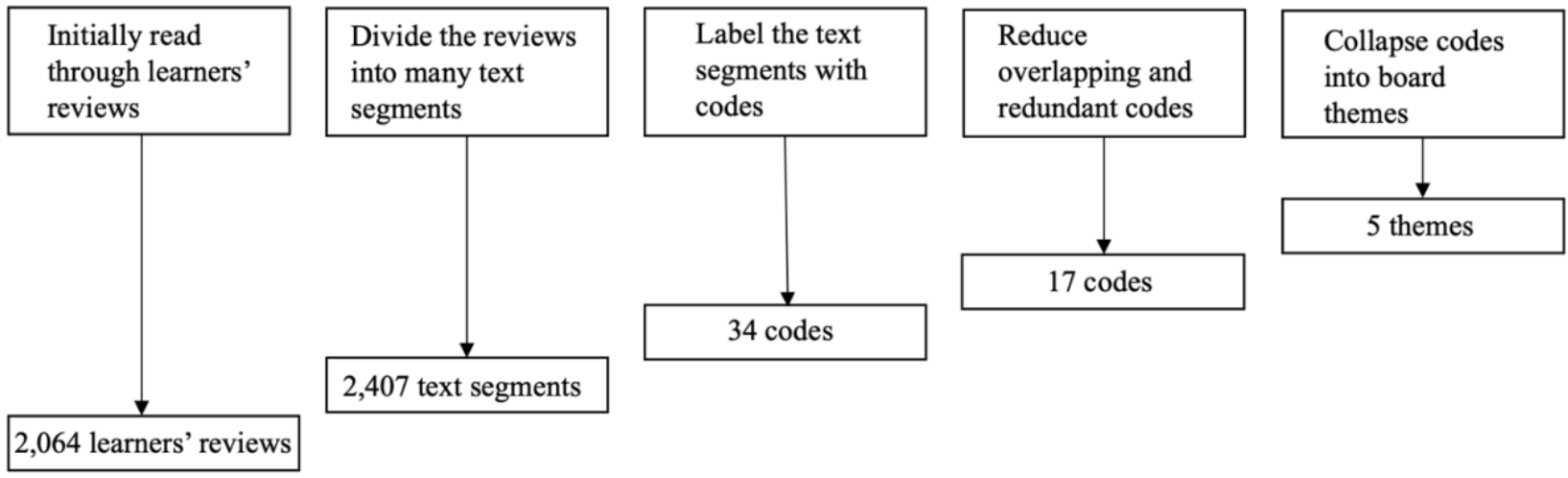

The method used to explore specific strategies offered by the mobile applications to promote learners' engagement was analytical evaluation. Such involves analyzing a system's features and their implications for use (Rosson \& Carrol, 2002). Based on the five critical factors yielded from learners' reviews and their subfactors, we carefully explored the relevant contents and features of the five identified mobile learning applications by browsing and operating these applications in person.

Specifically, we installed these applications on our phones and then operated them one by one as general learners. For each application, we first explored it by following its navigation 
menu to get familiar with it. Then, we searched available courses offered by it and randomly enrolled three courses. Next, we observed the contents and structures of these courses by carefully reading their introductions, browsing their curriculums, and taking them. In the whole analytical evaluation process, we primarily focused on those contents and features related to the identified five critical factors and their subfactors. Due to the nature of some critical factors, it is not always feasible to observe the corresponding strategies offered by these applications. As a result, only the factors whose strategies were observable through operating the identified mobile learning applications were included in this process.

\section{The Reliability Process}

We used a qualitative approach to establish consistency among the two authors' coding through extensive and frequent virtual discussions. Combined, the authors have extensive experience in teaching, learning technologies, learning design, human-computer interaction and in using inductive coding as a data analysis process. First, the reviews were reviewed individually by each author having the research questions in mind. After that, the authors met virtually to identify any levels of disagreement in relation to their analysis process and outcomes. The two authors reached consensus on which codes and themes to use in the analysis.

\section{Findings}

The following paragraphs present the findings of this study. The critical factors to learners' engagement in mobile learning applications (Udemy, LinkedIn Learning, Coursera, edX, and Skillshare) that emerged from the inductive analysis and the engagement strategies identified from the analytical evaluation are discussed.

What Factors are Critical to Learners' Engagement in Mobile Learning Applications?

The identified critical factors were:

1. Usability.

2. Availability of learning experiences (e.g., courses).

3. Features to facilitate learning.

4. Interpersonal interaction.

5. Incentives for completion.

As shown in Figure 4, usability $(68.97 \%)$ was the most frequently identified factor, followed by availability of learning experiences (17.45\%), features to facilitate learning $(9.93 \%)$, interpersonal interaction $(2.41 \%)$, and incentives for completion $(1.25 \%)$.

Figure 4

Distribution of analyzed text segments by factors impacting learners' engagement in mobile learning applications $(n=2,407)$

\begin{tabular}{|c|c|c|c|c|c|}
\hline \multirow{5}{*}{$\begin{array}{r}80.00 \% \\
60.00 \% \\
40.00 \% \\
20.00 \% \\
0.00 \%\end{array}$} & \multicolumn{5}{|c|}{$68.97 \%$} \\
\hline & & & & & \\
\hline & & $17.45 \%$ & $9.93 \%$ & 2410 & 10501 \\
\hline & & - & $\square$ & $2.41 \%$ & $1.25 \%$ \\
\hline & 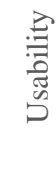 & 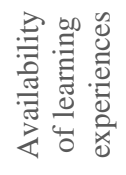 & 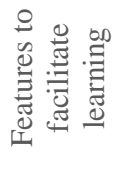 & 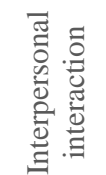 & 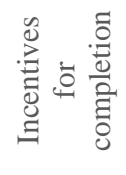 \\
\hline
\end{tabular}


Table 3 shows each factor studied in more detail through the codes used in the analysis. These codes were called subfactors. The cost of the applications was not included because we believed that cost is more relevant for business decisions than educational ones.

Table 3

Critical Factors Impacting Learners' Engagement and Corresponding SubFactors

\begin{tabular}{lcc}
\hline \multicolumn{1}{c}{ Factor/Subfactor } & $\begin{array}{c}\text { Number of } \\
\text { reviews }\end{array}$ & Percentage \\
\hline Usability & 1,236 & $74.46 \%$ \\
$\quad$ Learner satisfaction & 276 & $16.63 \%$ \\
Errors \& system stability & 103 & $6.20 \%$ \\
Ease of use & 45 & $2.71 \%$ \\
Loading time & 1,660 & $100.00 \%$ \\
Total & & \\
Availability of learning experiences & 266 & $63.33 \%$ \\
Course quality \& design & 108 & $25.71 \%$ \\
Course options \& coverage & 46 & $10.95 \%$ \\
Instructor expertise & 420 & $100.00 \%$ \\
Total & & \\
Features to facilitate learning & 89 & $37.24 \%$ \\
Learning on-the-go & 61 & $25.52 \%$ \\
Customized video play & 42 & $17.57 \%$ \\
Cross-platform functionality & 21 & $8.79 \%$ \\
Managing learning & 19 & $7.95 \%$ \\
Course capabilities & 7 & $2.93 \%$ \\
Note-taking capability & 239 & $100.00 \%$ \\
Total & & \\
Interpersonal interaction & 48 & $82.76 \%$ \\
Customer service support & 6 & $10.34 \%$ \\
Peer interaction & 4 & $6.90 \%$ \\
Instruction interaction/feedback & 58 & $100.00 \%$ \\
Total & & \\
Incentives for completion & 30 & $100.00 \%$ \\
Certifications/degrees & 30 & $100.00 \%$ \\
Total & & \\
\hline & & \\
\hline
\end{tabular}

Regarding usability, learner satisfaction $(74.46 \%)$ was the most frequent subfactor, followed by errors and system stability $(16.63 \%)$, ease of use $(6.20 \%)$, and loading time $(2.71 \%)$. Learner satisfaction refers to the user's likeability of the system. Errors mentioned by learners were related to video downloads, offline mode, sign-in process, payment process, video playback functionality, and overall stability of the app. In terms of ease of use, it mostly about interface design and navigability. Learners' reviews regarding loading time mainly focused on video loading time and application loading time.

Course quality and design (63.33\%), course options and coverage $(25.71 \%)$, and instructor expertise $(10.95 \%)$ were the three subfactors under the availability of learning experiences. The attributes regarding course quality and design included learning content, audio and video quality, learning duration, and opportunities for practice. In terms of course options and coverage, learners preferred mobile learning applications that offer many courses with different topics. Besides, learners preffered applications with highly professional instructors. 
Features to facilitate learning included six subfactors:

1. Learning on-the-go (37.24\%).

2. Customized video play $(25.52 \%)$.

3. Cross-platform functionality $(17.57 \%)$.

4. Managing learning $(8.79 \%)$.

5. Course capabilities (7.95\%).

6. Note-taking capability (2.93\%).

Learning on-the-go was primarily related to downloading files and offline working. Customized video play included speed change, background or audio-only play, closed captioning, and screen rotation. In terms of cross-platform functionality, attributes raised by learners involved video casting, information syncing, and operational consistency. Moreover, learners mentioned that the course organization and process saving functions effectively helped them manage their learning. Course capabilities refer to the abilities of mobile learning applications to help learners discover the desired courses. The higher the course capabilities, the easier it is for learners to find the learning content. Additionally, learners highlighted the importance of note-taking capability for their learning.

When it comes to interpersonal interaction, the majority of reviews were related to customer service support $(82.76 \%)$, followed by peer interaction $(10.34 \%)$, and instructor interaction $(6.90 \%)$. When faced with problems, learners preferred easy access to customer service. Also, they mentioned the importance of interacting with a peer, such as participating in discussion, collaborative working, and interacting with instructors, such as contacting instructors and receiving feedback.

Incentives for completion include the internal motivation and external motivation of a user to accomplish something. In this study, external motivation was the main focus because could directly promote it by optimizing the design of mobile learning applications. In learners' reviews, certifications and degrees issued by learning applications were mentioned many times, which shows the value learners attached to them. Table 4 presents the examples of learners' reviews.

Table 4

Examples of Learners' Reviews

Usability Factor/Subfactor Examples

Learners' satisfaction

This app and the courses are fantastic. The best professional education application.

Error \& system stability

I have downloaded the video, but I couldn't access it offline.

Have been trying to put in my credit card details, but it keeps telling me invalid card.

When watching video, the main screen (slide) is not showing. After the recent update, the [name of the app] crashed and isn't opening.

Ease of use

Loading time

Availability of learning

experiences

Course quality \& design I am super satisfied with all the dynamic interface and software platform. Most of the videos are not loading or take too much time to load. The app is a bit slow to open at the start.

Demo video is good after that I bought a course very low audio and video quality very worst.

Courses were designed for shorter duration which is keeping the viewers motivated to watch. 
Course options \& coverage

Instructor expertise

Features to facilitate learning

Learning on-the-go

Customized video play

Cross-platform functionality

Managing learning

Course capabilities

Note-taking capability

Interpersonal interaction

Customer service support

Peer interaction

Instructor interaction

Incentives for completion

certifications/degrees
It is very good educational app, but it could be improved by adding some exercises or quizzes between each lecture to practice what we have learnt.

There is a huge variety of videos.

Teachers are knowledgeable and easily to understand.

Very great on mobile with the offline downloadable features.

There should be an option for incremental speed using 10 steps or 5 steps instead of 25 steps.

I love that there is an audio only option.

Great, but it should have a tool for subtitles.

This app really missing some features like ... being able to rotate the screen in any direction.

I miss the ability of streaming/casting videos from the app directly to my TV.

The synchronization works well.

Can you please keep some additional filters in "My Course?"

Saves your progress for easy access when you're coming back.

There should be more options through the app to explore new categories and topics.

Would be nice to listen to lectures and take notes at the same time.

Super quick response on the weekend and my issue was quickly resolved.

The discussion groups look pretty good, but I rarely participate.

Wish there was a channel inside the platform where I could connect with the teacher/coach on time.

Great app, always looking for learning and certifications on different subjects.

\section{Which Engagement Strategies are Offered by Mobile Learning Applications that Promote Learners' Engagement?}

Based on the identified critical factors and their subfactors, the specific strategies provided by Udemy, LinkedIn Learning, Coursera, edX, and Skillshare to promote learners' engagement are discussed below.

\section{Engagement Strategies Regarding Availability of Learning Experiences}

In terms of availability of learning experience, the five examined applications provided learners with general descriptions about their courses, including:

1. Course provider (instructor's qualifications and/or affiliated institution).

2. Course introduction (in text and/or video format).

3. Course features (e.g., rating, number of enrollments, total length, learning level).

4. Course structure.

Although the general descriptions deviated among these applications, it allowed learners to have a straightforward impression of the quality and popularity of the courses.

A varity of learning materials can enhance learners' engagement and learning outcome (Hew, 2016; Sadaf et al., 2019). The analyzed applications typically offered courses containing different learning materials in multiple formats, such as short videos, auto-graded quizzes, and selected readings. Auto-graded quizzes with multiple attempts help learners reinforce learning. Some courses in Coursera, edX, LinkedIn Learning, and Udemy offered supplemental learning 
materials to allow learners to go deeper into specific topics. According to Freitas et al. (2015), learners are more engaged when receiving interactive digital learning content. Coursera and edX provided interactive videos to attract learners' attention.

Regarding course options and coverage, these mobile learning applications offered a wide range of courses and/or modules across different subjects to meet learners' diverse learning interests and goals. Coursera and LinkedIn Learning offered courses from various countries, and LinkedIn Learning and Udemy released new learning experiences periodically. Except for taking individual courses, learners also had opportunities to obtain degrees through Coursera and edX.

Instructor expertise brings credibility to the courses and relates to the course quality. Therefore, learners believe that instructor self-introduction impact their learning and engagement (Sadaf et al., 2019). The analyzed applications provided each instructor's basic information, such as name, title, organization, career, and educational background, on the course page taught by him/her. Also, LinkedIn Learning provided the link to each instructor's LinkedIn profile, and Udemy provided each instructor's learner amount, course amount, average rating, and contact information. This information allowed learners to know more about their instructors.

\section{Engagement Strategies Regarding Features to Facilitate Learning}

Downloadable learning materials facilitate online learning by avoiding internet lag or system crash (Hew, 2016). Through providing downloadable materials, the analyzed applications enabled learners to utilize their fragmented time to learn offline. Additionally, cross-platform video casting and information synchronization delivered learners more options and consistency. For example, most applications enabled learners to cast course videos from mobile devices to other devices, such as TV, speaker, etc. Thus, learners could get a better audio-visual experience. Some applications automatically synced learners' courses and learning progress between different platforms to equip learners with more choices on learning devices without worrying about consistency problems.

Mobile learning engagement can be promoted when learners have a personalized adaptive learning experience (Pham \& Chen, 2019). To meet learners' personalized video playback needs, most of these applications made the following options available: play/pause, forward/back, subtitles on/off, full-screen play with automatic screen rotation, speed changes, and background play. Additionally, learners could change video quality on Udemy, used the picture-in-picture function on LinkedIn Learning, and viewed video transcripts with auto sliding text on Coursera and edX. Selecting appropriate ways to play course videos can enhance learners' learning and satisfy their unique learning needs. Coursera and Udemy, in particular, also allowed learners to take notes while watching videos. Those notes could be saved with corresponding video clips. Therefore, learners could recap previous contents by viewing their notes and the relevant video clips.

These applications automatically saved learners' learning progress. Learners could stop learning at any time and started from where they left without worrying about losing previous progress. If offline learning progress could not be automatically tracked, Udemy allowed learners to mark courses as completed manually. Furthermore, learners could set up reminders in Coursera, LinkedIn Learning, Udemy, and Skillshare to keep them on track. If learners enrolled in many courses or took a large number of notes, they could quickly find the materials they need by using the search bar, course filter, or sorting function available on Udemy.

Learning activities revolve around the course learners are taking; therefore, what courses learners can find will directly determine learners' learning experiences. The analyzed applications allowed learners to find courses through the search bar, course topics, and course 
categories to facilitate the course searching process. EdX, LinkedIn Learning, and Udemy provided course filters to help learners narrow their search. Most of these applications recommended courses to learners based on their interests, searching history, and viewed courses through algorithms. On LinkedIn Learning, Udemy, and Skillshare, if learners were interested in a particular instructor, they could find all courses offered by the instructor on the instructor's introduction page. According to McLean (2018), the ease of use of a mobile application positively impacts customers' engagement with it.

\section{Engagement Strategies Regarding Interpersonal Interaction}

Facilitating conditions, the degree to which users believe that an organizational and technical infrastructure exists to support use of a system, is a critical factor impacting users' adoption of a system (Venkatesh et al., 2003). To create facilitating conditions for using mobile learning applications, these applications enabled learners to get in touch with customer support in different ways, such as through help centers, social media, and email and helped them solve the problems encountered in using. On each course's homepage, Coursera also listed the frequently asked questions and answers about that course.

Peer interation is critical to enhance learners' engagement in online environments (Guajardo Leal et al., 2019). To promote peer interaction, these applications allowed learners to share courses through a link. Each course also had a discussion/Q\&A forum on its homepage. Some courses on Coursera and edX contained peer-review assignments. Moreover, Coursera and Skillshare allowed learners to view and interact with peers' feedback. Learners of LinkedIn Learning and Skillshare could get necessary information about their peers by clicking on others' avatars. LinkedIn Learning also revealed the typical job titles of learners enrolled in the same course.

Learner-to-instructor interaction also plays an important role in facilicating learners'engagement in online environments (Martin \& Bolliger, 2018). In addition to asking questions on the discussion/Q\&A forum mentioned above, learners could also receive feedback and announcements from instructors in some courses. Besides, LinkedIn Learning and Udemy allowed learners to contact instructors by making instructors' contact information available directly, and Skillshare let learners follow instructors' accounts to get updated information.

\section{Engagement Strategies Regarding Incentive for Completion}

Completion certificates encourage learners to coutinue using mobile learning applications by creating clear goals and enjoyable learning challenges (Pham \& Chen, 2019). Coursera, edX, Udemy, and LinkedIn Learning provided course completion certificates to learners. Although not all certificates could be used for formal accreditation, such as certificates issued by LinkedIn Learning and Udemy, they were intuitive incentives to motivate learners to complete their studies. Using the certificate-issuing feature, these certificates could be published directly on learners' LinkedIn or other social media platforms and be downloaded and printed. Therefore, learners could easily add them to their CVs, resumes, or other documents.

Alternatively, Skillshare useed completed course projects as its unique completion incentive. Learners of Skillshare needed to complete a project for every enrolled course, and could display the completed project on the course's homepage to demonstrate their mastery of specific skills. Additionally, the analyzed applications informed learners of the knowledge they would obtain after completing a course, which helped learners understand their learning outcomes. 


\section{Discussion}

The results of this study further expanded Hew's (2016) model of learners' engagement, as shown in Figure 5. Because the relations between the self-determination theory and learners' engagement were adopted from Hew (2016), we mainly elaborated the relations newly developed in this study below, which were the relations between the five factors emerging from this study and the self-determinate theory.

In this study, usability involves learners' satisfaction, errors and system stability, ease of use, and loading time. Because usability refers to how easy it is for users to learn to operate and use a system (IEEE, 1990), it directly impacts learners' use of mobile learning applications and affects the completion of tasks that learners desire. If an application is hard to operate, crashes all the time, or cannot load learning materials, learners cannot use it. Consequently, the completion of learning tasks and the achievement of learning goals are also be hindered. As a result, usability caters to learners' need for autonomy and competence.

Figure 5

Model of Relations Among Identified Factors, Self-Determinate Theory, and Learners' Engagement Expanded from Hew's (2016) Model

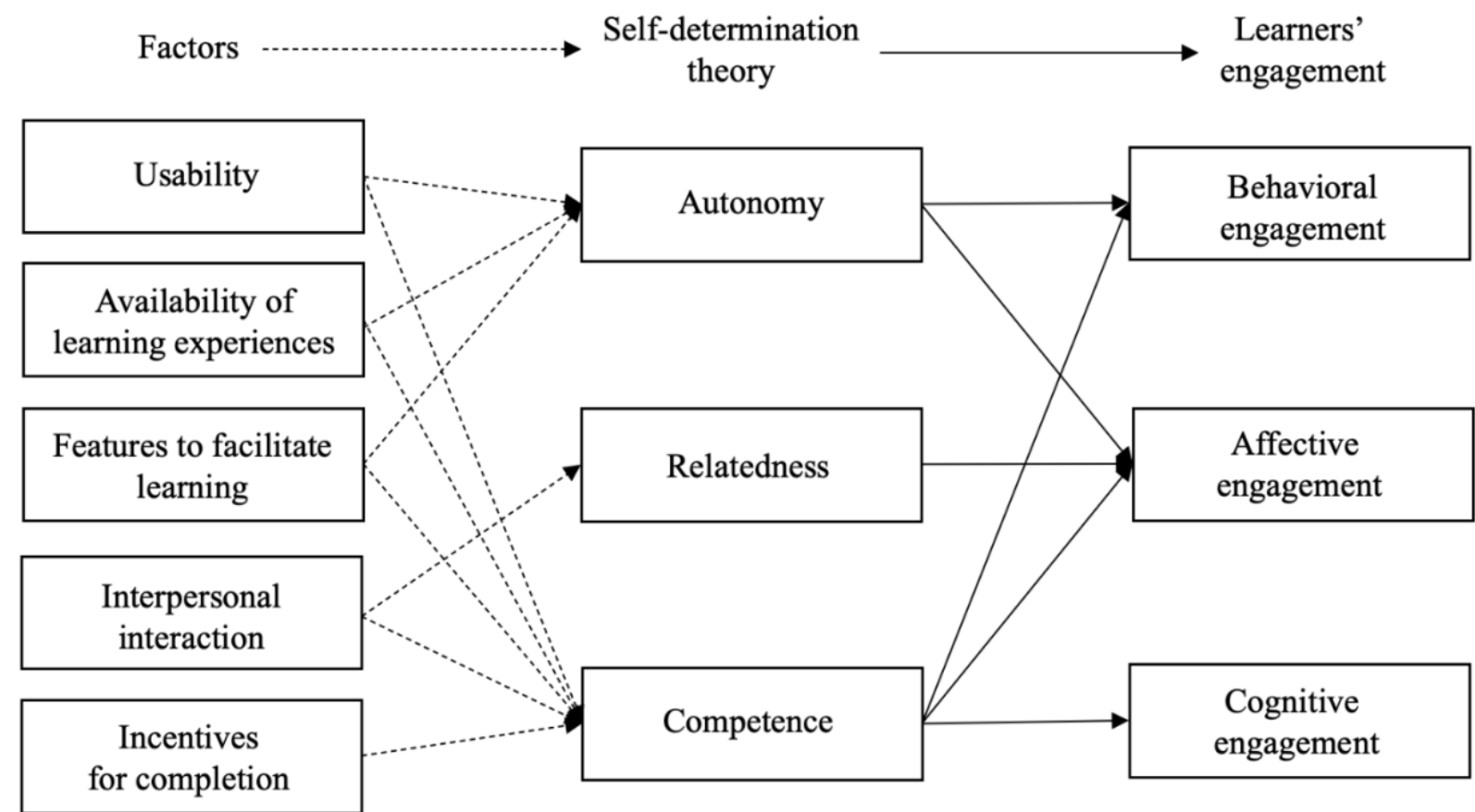

Note. The solid lines indicate the relations from Hew's model, while the dashed lines indicate the relations proposed in this study.

Course quality and design as well as instructor expertise are two of the subfactors of availability of learning experiences. High-quality and well-designed courses can ensure excellent course content, thereby increasing learning engagement and learning outcome (e.g., Hew, 2016; Sadaf et al., 2019). And professional instructors can facilitate the efficient delivery of the course content. Hence, the two subfactors play an essential role in learners' learning and can impact learners' knowledge acquisition, which caters to learners' need for competence. Also, when 
courses offered through mobile learning applications provided a high number and variety of topics, learners have more learning choices, which meets their need for autonomy.

The features to facilitate learning include six subfactors: learning on-the-go, customized video play, cross-platform functionality, manage learning, note-taking capability, and course capability. The first three allow learners to freely choose their learning location and time, videoplaying methods, and learning devices, fostering a sense of autonomy. The last three subfactors facilitate learners' learning and enable learners to organize their learning better. Therefore, it can also foster a sense of competence.

In terms of interpersonal interaction, it serves learners' needs for relatedness and competence. Through acquiring adequate customer support, communicating with peers and instructors, learners can build social connections with others (e.g., Freitas et al., 2015; Hew, 2016). Asking learning-related questions and getting feedback from peers and instructors can also improve learners' learning.

Last but not least, incentives for completion fosters learners' sense of competence. In this study, incentives for completion were expressed in different forms, such as certificates, degrees, or completed projects. These incentives are intuitive rewards for learners, which can boost learning motivation. Therefore, this factor can meet learners' competence needs.

\section{Implications}

The findings of this case study suggest that factors impacting learners' engagement in education and factors affecting customers' engagement in mobile applications both matter to learners of mobile learning applications. For example, previous studies from the education field (Martin \& Bolliger, 2018) and the marketing field (Lele, 2015; Dinner et al., 2015) recognized the importance of interpersonal interaction to learners/customers' engagement. This factor is also highlighted in this study. Achievement motivation (Zepke \& Leach, 2010) and accomplishment rewards (Pham \& Chen, 2019) match this study's incentives for completion factor. Hegarty and Thompson (2019) mentioned the impact of curriculum \& learning design on learners' engagement. This viewpoint relates to the availability of learning experiences in this study. Besides, ease of use (McLean, 2018; Fang et al., 2017) and compatibility (Kim \& Baek, 2018; McLean, 2018; Fang et al., 2017) emphasized in previous studies also correspond to this study's usability and features to facilitate learning respectively.

Although this study primarily focuses on learners' engagement, its findings corroborate the foundational variables of mobile learning application quality suggested by Pongwat (2019). These foundational variables are pedagogical, functionality, performance, usability, support, security, portability, communication, and synchronization. For example, this study's usability factor relates to the foundational variables labeled performance, usability, and security. The availability of learning experiences (e.g., courses) corresponds to the pedagogical foundation. Features to facilitate learning match the foundational variables named functionality, portability, and synchronization. Interpersonal interaction corresponds to the communication and support variables. Therefore, this study also provides implications for the analysis of mobile learning applications' educational quality. In the current study, the subfactor of usability, namely system errors, revolved around video downloads, offline mode, sign-in, payment processes, video playback functionality, and overall stability of applications. These errors are similar to the weaknesses of mobile learning applications recognized by Pongwat (2019). Therefore, it can be concluded that they are common errors in mobile learning applications. Researchers and professionals in related fields should pay special attention to them. 
This study contributes to the design and development of mobile learning applications with higher levels of learners' engagement. The revealed specific engagement strategies, such as providing different learning material formats, automatically syncing the learning process between other platforms, and offering discussion/Q\&A forums for interpersonal interaction, offer practical guidelines to mobile learning application designers. The identified five factors and the expanded Hew's (2016) model also offer theoretical implications for further research regarding learners' engagement in mobile learning applications.

\section{Limitations}

However, there are some limitations to the current study. The sample consisted of five top-ranked lifelong mobile learning applications, which cannot represent all types of mobile learning applications. Future research can investigate more applications to broaden or strengthen the findings of this study. Moreover, this study only analyzed the public reviews posted on App Store and Google Play. As a result, the findings of this study may have limitations. Future research can also explore the standpoint of learners who did not post their reviews online. The current study proposed a model that suggests the interrelations among identified factors between self-determination theory and learners' engagement. However, this model is to be further verified by research that employs quantitative approaches.

\section{Conclusion}

Through focusing on learners' engagement in lifelong learning mobile applications and proposing a model that suggests the interrelations among identified factors, self-determinate theory, and learners' engagement, this study emphasized the importance of combining learning design in mobile learning. The five identified factors (usability, availability of learning experiences, features to facilitate learning, interpersonal interaction, and incentives for completion) comprehensively explain how to improve learners' engagement in mobile learning applications from multiple perspectives, such as education, mobile application design, and marketing.

\section{Declarations}

The author(s) declare that there is no conflict of interest in this study.

The authors received approval from the ethics review board of The Ohio State University, USA for this study.

The author received no financial support for the research, authorship, and/or publication of this article. 


\section{References}

Ansari, M. S., \& Tripathi, A. (2017). An investigation of effectiveness of mobile learning apps in higher education in India. International Journal of Information Studies \& Libraries, 2(1), 33-41.

AppGrooves. (n.d.). About AppGrooves. https://appgrooves.com/about

Aspin, D. N., \& Chapman, J. D. (2000) Lifelong learning: concepts and conceptions. International Journal of Lifelong Education, 19(1), 2-19.

Baker, O. (2020, March 24). 8 Mobile App Retention Strategies For 2020 [With Examples]. Web Engage. https://webengage.com/blog/mobile-app-retention-strategies/

Bond, M., Buntins, K., Bedenlier, S., Zawacki-Richter, O., \& Kerres, M. (2020). Mapping research in student engagement and educational technology in higher education: A systematic evidence map. International Journal of Educational Technology in Higher Education, 17(2), 130. https://doi.org/10.1186/s41239-019-0176-8

Brodie, R. J., Hollebeek, L. D., Jurić, B., \& Ilić, A. (2011). Customer engagement: Conceptual domain, fundamental propositions, and implications for research. Journal of Service Research, 14(3), 252-271. https://doi.org/10.1177/1094670511411703

Buelow, J. R., Barry, T. A., \& Rich, L. E. (2018). Supporting learning engagement with online students. Online Learning, 22(4), 313-340. https://doi.org/10.24059/olj.v22i4.1384

Chee, K. N., Yahaya, N., Ibrahim, N. H., \& Hasan, M. N. (2017). Review of mobile learning trends 2010-2015: A Meta-Analysis. Journal of Educational Technology \& Society, 20(2), 113126. https://www.jstor.org/stable/10.2307/90002168

Chen, R., Wang, Q., \& Xu, W. (2019). Mining user requirements to facilitate mobile app quality upgrades with big data. Electronic Commerce Research and Applications, 38, 1-11. https://doi.org/10.1016/j.elerap.2019.100889

Cheung, C., Lee, M., \& Jin, X. (2011). Customer engagement in an online social platform: A conceptual model and scale development. International Conference on Information Systems 2011 Proceedings. 8. https://aisel.aisnet.org/icis2011/proceedings/onlinecommunity/8

Coates H., \& Radloff A. (2012) Measurement of student engagement in learning. In N. M. Seel (Ed.), Encyclopedia of the Sciences of Learning. Springer. https://doi.org/10.1007/978-1-44191428-6_923

Cooke, A. N., Fielding, K. S., \& Louis, W. R. (2016). Environmentally active people: The role of autonomy, relatedness, competence and self-determined motivation. Environmental Education Research, 22(5), 631-657. https://doi.org/10.1080/13504622.2015.1054262 
Creswell, J. W. (2012). Educational research: Planning, conducting, and evaluating quantitative and qualitative research (4th ed.). Pearson. https://www.pearson.com/us/highereducation/product/Creswell-Educational-Research-Planning-Conducting-and-EvaluatingQuantitative-and-Qualitative-Research-4th-Edition/9780131367395.html

Davis, T., \& Frederick, T. V. (2020). The impact of multimedia in course design on students' performance and online learning experience: A pilot study of an introductory educational computing course. Online Learning, 24(3), 147-162. https://doi.org/10.24059/olj.v24i3.2069

Deci, E. L., \& Ryan, R. M. (2008). Self-determination theory: A macrotheory of human motivation, development, and health. Canadian Psychology/Psychologie canadienne, 49(3), 182-185. https://doi.org/10.1037/a0012801

Deb, D., Fuad, M. M., \& Kanan, M. (2017). Creating engaging exercises with mobile response system (MRS). Proceedings of the 2017 ACM SIGCSE Technical Symposium on Computer Science Education. https://doi.org/10.1145/3017680.3017793

Freitas, S. I., Morgan, J., \& Gibson, D. (2015). Will MOOCs transform learning and teaching in higher education? Engagement and course retention in online learning provision. British Journal of Educational Technology, 46(3), 455-471. https://doi.org/10.1111/bjet.12268

Dinner, I. M., van Heerde, H. J., \& Neslin, S. (2015). Creating customer engagement via mobile apps: How app usage drives purchase behavior. Tuck School of Business Working Paper No. 2669817. https://doi.org/10.2139/ssrn.2669817

Fang, J., Zhao, Z., Wen, C., \& Wang, R. (2017). Design and performance attributes driving mobile travel application engagement. International Journal of Information Management, 37(4), 269-283. https://doi.org/10.1016/j.ijinfomgt.2017.03.003

Fredricks, J. A., Blumenfeld, P. C., \& Paris, A. H. (2004). School engagement: Potential of the concept, state of the evidence. Review of Educational Research, 74(1), 59-109. https://doi.org/10.3102/00346543074001059

Fredricks, J. A., Filsecker, M., \& Lawson, M. A. (2016). Student engagement, context, and adjustment: Addressing definitional, measurement, and methodological issues. Learning and Instruction, 43, 1-4. https://doi.org/10.1016/j.learninstruc.2016.02.002

Guajardo Leal, B. E., Valenzuela González, J. R., \& Scott, J. (2019). Student engagement as predictor of xMOOC Completion: An analysis from five courses on energy sustainability. Online Learning, 23(2), 105-123. https://doi.org/10.24059/olj.v23i2.1523

Guenther, C. L., \& Miller, R. L. (2011). Factors that promote engagement. In R. L. Miller, E. Amsel, B. M. Kowalewski, B. C. Beins, K. D. Keith, \& B. F. Peden (Eds.), Promoting student engagement (Vol. 1, pp. 10-17). Society for the Teaching of Psychology. https://cpltl.iupui.edu/doc/Miller\%20et\%20al_2011.pdf 
Hannon, K. (2017). Utilization of an educational web based mobile app for acquisition and transfer of critical anatomical knowledge, thereby increasing classroom and laboratory preparedness in veterinary students. Online Learning, 21(1), 201-208.

https://eric.ed.gov/?id=EJ1140261

Harman, M., Jia, Y., \& Zhang, Y. (2012). App store mining and analysis: MSR for app stores. 2012 9th IEEE Working Conference on Mining Software Repositories (MSR), 108-111. https://doi.org/10.1109/msr.2012.6224306

Harris, L. R. (2008). A phenomenographic investigation of teacher conceptions of student engagement in learning. The Australian Educational Researcher, 35(1), 57-79. https://doi.org/10.1007/BF03216875

Hegarty, B., \& Thompson, M. (2019). A teacher's influence on student engagement: Using smartphones for creating vocational assessment ePortfolios. Journal of Information Technology Education: Research, 18, 113-159. https://doi.org/10.28945/4244

Hew, K. F. (2016). Promoting engagement in online courses: What strategies can we learn from three highly rated MOOCS: Engagement: lessons from MOOCs. British Journal of Educational Technology, 47(2), 320-341. https://doi.org/10.1111/bjet.12235

Hollebeek, L. (2011). Exploring customer brand engagement: definition and themes. Journal of Strategic Marketing, 19(7), 555-573. https://doi.org/10.1080/0965254x.2011.599493

Hong, Y., \& Gardner, L. (2019). Undergraduates' perception and engagement in Facebook learning groups. British Journal of Educational Technology, 50(4), 1831-1845. https://doi.org/10.1111/bjet.12672

Hwang, G. J., \& Wu, P. H. (2014). Applications, impacts and trends of mobile technologyenhanced learning: A review of 2008-2012 publications in selected SSCI journals. International Journal of Mobile Learning and Organisation, 8(2), 83-95. https://doi.org/10.1504/ijmlo.2014.062346

IEEE. (1990). IEEE standard glossary of software engineering terminology. IEEE Std 610.121990, 1-84. https://doi.org/10.1109/ieeestd.1990.101064

Khalid, H., Shihab, E., Nagappan, M., \& Hassan, A. E. (2015). What do mobile app users complain about? IEEE Software, 32(3), 70-77. https://doi.org/10.1109/ms.2014.50

Kim, S., \& Baek, T. H. (2018). Examining the antecedents and consequences of mobile app engagement. Telematics and Informatics, 35(1), 148-158.

https://doi.org/10.1016/j.tele.2017.10.008

Kuh, G. D. (2001). Assessing what really matters to student learning: Inside the National Survey of Student Engagement. Change: The Magazine of Higher Learning, 33(3), 10-17. https://doi.org/10.1080/00091380109601795 
Lele, S. (2015, March 2). 8 Tips for Boosting App Retention: Create an App for the Long Run. Business 2 Community. https://www.business2community.com/mobile-apps/8-tips-boostingapp-retention-create-app-long-run-01172687

Martin, F., \& Bolliger, D. U. (2018). Engagement matters: Student perceptions on the importance of engagement strategies in the online learning environment. Online Learning, 22(1), 205-222. https://doi.org/10.24059/olj.v22i1.1092

McLean, G. (2018). Examining the determinants and outcomes of mobile app engagement-A longitudinal perspective. Computers in Human Behavior, 84, 392-403. https://doi.org/10.1016/j.chb.2018.03.015

Nielsen, J. (1993). Usability engineering. Morgan Kaufmann.

Mobile Operating System Market Share Worldwide. (December 2020). statcounter GolbalStats. https://gs.statcounter.com/os-market-share/mobile/worldwide

Noel, D., Stover, S., \& McNutt, M. (2015). Student perceptions of engagement using mobilebased polling as an audience response system: Implications for leadership studies. Journal of Leadership Education, 14(3), 53-70.

Pechenkina, E., Laurence, D., Oates, G., Eldridge, D., \& Hunter, D. (2017). Using a gamified mobile app to increase student engagement, retention and academic achievement. International Journal of Educational Technology in Higher Education, 14(1), 1-12. https://doi.org/10.1186/s41239-017-0069-7

Pham, X. L., \& Chen, G. D. (2019). PACARD: A new interface to increase mobile learning app engagement, distributed through app stores. Journal of Educational Computing Research, 57(3), 618-645. https://doi.org/10.1177/0735633118756298

Pham, X. L., Nguyen, T. H., Hwang, W. Y., \& Chen, G. D. (2016). Effects of push notifications on learner engagement in a mobile learning app. 2016 IEEE 16th International Conference on Advanced Learning Technologies (ICALT), 90-94. https://doi.org/10.1109/icalt.2016.50

Pongwat, A. (2019). Investigating the voice of customers for m-learning application quality. Proceedings of the European Conference on E-Learning, 486-494. https://doi.org/10.34190/EEL.19.071

Qiu, J. (2019). A review of mobile learning research at home and abroad in recent 20 years. Journal of Language Teaching \& Research, 10(5), 1097-1102. https://doi.org/10.17507/jltr.1005.24

Reeve J. (2012) A self-determination theory perspective on student engagement. In S. L. Christenson et al. (Eds), Handbook of Research on Student Engagement (pp. 149-172). Springer. https://doi.org/10.1007/978-1-4614-2018-7_7 
Rosson, M. B., \& Carroll, J. M. (2002). Usability engineering: Scenario-based development of human-computer interaction. Academic Press.

Sadaf, A., Martin, F., \& Ahlgrim-Delzell, L. (2019). Student perceptions of the impact of quality matters-certified online courses on their learning and engagement. Online Learning, 23(4), 214 233. https://doi.org/10.24059/olj.v23i4.2009

Statista Research Department. (2021, July 6). Mobile app user retention rate worldwide 2020, by vertical. Statista. https://www.statista.com/statistics/259329/ios-and-android-app-user-retentionratel

Sun, Y., Ni, L., Zhao, Y., Shen, X. L., \& Wang, N. (2019). Understanding students' engagement in MOOCs: An integration of self-determination theory and theory of relationship quality.

British Journal of Educational Technology, 50(6), 3156-3174.

https://doi.org/10.1111/bjet.12724

Tarantino, K., McDonough, J., \& Hua, M. (2013). Effects of student engagement with social media on student learning: A review of literature. The Journal of Technology in Student Affairs, $1(8), 1-8$.

http://www.studentaffairs.com/ejournal/Summer_2013/EffectsOfStudentEngagementWithSocial

Media.html

Tarute, A., Nikou, S., \& Gatautis, R. (2017). Mobile application driven consumer engagement. Telematics and Informatics, 34(4), 145-156. https://doi.org/10.1016/j.tele.2017.01.006

Thomas, D. R. (2006). A general inductive approach for analyzing qualitative evaluation data. American Journal of Evaluation, 27(2), 237-246. https://doi.org/10.1177/1098214005283748

Trowler, V. (2010). Student engagement literature review. The Higher Education Academy. https://www.advance-he.ac.uk/knowledge-hub/student-engagement-literature-review

Tucker, C., \& Kim, H. M. (2011). Predicting emerging product design trend by mining publicity available customer review data. 18th International Conference on Engineering Design (ICED11), 6, 43-52.

Venkatesh, V., Morris, M. G., Davis, G. B., \& Davis, F. D. (2003). User acceptance of information technology: Toward a unified view. MIS Quarterly, 27(3), 425-478.

https://doi.org/10.2307/30036540

Vivek, S. D., Beatty, S. E., \& Morgan, R. M. (2012). Customer engagement: Exploring customer relationships beyond purchase. Journal of Marketing Theory and Practice, 20(2), 122-146. https://doi.org/10.2753/mtp1069-6679200201

Wu, W., Wu, Y. J., Chen, C., Kao, H., Lin, C., \& Huang, S. (2012). Review of trends from mobile learning studies: A meta-analysis. Computers \& Education, 59(2), 817-827. https://doi.org/10.1016/j.compedu.2012.03.016 
Zepke, N., \& Leach, L. (2010). Improving student engagement: Ten proposals for action. Active Learning in Higher Education, 11(3), 167-177. https://doi.org/10.1177/1469787410379680

Zhang, H., Lin, L., Zhan, Y., \& Ren, Y. (2016). The Impact of teaching presence on online engagement behaviors. Journal of Educational Computing Research, 54(7), 887-900. https://doi.org/10.1177/0735633116648171

Zuniga, A., Flores, H., Lagerspetz, E., Tarkoma, S., Manner, J., Hui, P., \& Nurmi, P. (2019). Tortoise or Hare? quantifying the effects of performance on mobile app retention. In Proceedings of the 2019 World Wide Web Conference (WWW'19) (pp. 2517-2528). https://doi.org/10.1145/3308558.3313428 